\title{
Influence of rifampin therapy on serum bactericidal activity in the presence of cloxacillin and vancomycin
}

ANDREW MR MACKENZIE, MD, FRCPC, NONI E MACDONALD, MD, FRCPC

ABSTRACT: In this study the effect of rifampin on serum inhibitory and serum bactericidal titres was examined. Sera were prepared from pooled human serum to contain vancomycin (10 mg/L), cloxacillin (5 $\mathrm{mg} / \mathrm{L}$ ) or rifampin (1 $\mathrm{mg} / \mathrm{L})$, and the combinations cloxacillin/rifampin and vancomycin/rifampin. These five sera were tested by a microtitre method for serum inhibitory power and serum bactericidal titre against 11 strains of Staphylococcus aureus. A 48 h incubation period was required to detect full colony growth for subculture plates. It was found with all strains that the effect of the addition of rifampin to the other two antibiotics was to increase the serum inhibitory power, lower the serum bactericidal titre, increase the inhibitory/cidal ratio, and slow colony growth on subculture. In the clinical part of the study it was shown that only three of 38 sera $(8 \%)$ from patients receiving betalactam or vanomycin but not rifampin gave an inhibitory/cidal ratio greater than 8 , but that nine of 10 sera $(90 \%)$ from patients receiving rifampin in addition to betalactam or vancomycin gave a ratio greater than $8(\mathrm{P}<0.001)$. The study verified that the effect of rifampin in serum was to increase inhibitory power and decrease bactericidal titre. The clinical significance of these results is not known and it is suggested that a high ratio of inhibitory to bactericidal titre in the presence of rifampin is to be expected, and that a low bactericidal titre under these circumstances is not necessarily an indication to modify therapy. Can J Infect Dis 1990;1(2):41-47

Key Words: Cloxacillin, Rifampin, Serum bactericidal, Staphylococcus aureus, Vancomycin
$S_{\text {tires }}^{\text {ह }}$ ERUM INHIBITORY POWER AND SERUM BACTERICIDAL titre are commonly used tests of the efficacy of antimicrobial therapy in the management of serious systemic infections (1). In the authors' laboratory these tests have often been used in monitoring therapy for infections due to Staphylococcus aureus. In the course of performing these tests it was noted that sera from patients

Department of Laboratory Medicine, Children's Hospital of Eastern Ontario, Ottawa, Ontario

Correspondence and reprints: Dr AMR MacKenzie,

Department of Laboratory Medicine, Children's Hospital of

Eastern Ontario, 401 Smyth Road, Ottawa, Ontario K1H 8L1.

Telephone (613) 737-2543

Received for publication February 7, 1990. Accepted April 3,1990 receiving rifampin showed a high serum inhibitory power but a low serum bactericidal titre. This has been reported by previous investigators (2-4). It was also noticed that with the same sera, subculture plates from the serum bactericidal titre tests sometimes required a $48 \mathrm{~h}$ incubation time for full development of surviving colonies. This in vitro and clinical study was designed to investigate this problem.

\section{MATERIALS AND METHODS}

Strains and materials for in vitro study: Ten strains from patients with significant Staph aureus infections were selected at random from the author's laboratory collection. Strain ATCC 25923 was also included in this series. All strains 
were susceptible to oxacillin by the standard National Committee for Clinical Laboratory Standards (NCCLS) agar disk diffusion test. The following antibiotic powders were obtained from their respective manufacturers: cloxacillin (Bristol Laboratories), rifampin (CIBA Pharmaceuticals) and vancomycin (Eli Lilly Canada Inc). Fresh cloxacillin solutions were made up for each experiment. Rifampin and vancomycin were stored at $-70^{\circ} \mathrm{C}$ as stock solutions.

Experimental tests: Antibiotics were added to a single batch of pooled human sera at the following concentrations: cloxacillin $5 \mathrm{mg} / \mathrm{L}$, vancomycin 10 $\mathrm{mg} / \mathrm{L}$ and rifampin $1 \mathrm{mg} / \mathrm{L}$. The NCCLS method proposes pooled human serum as a diluent (5), but in the present study Mueller-Hinton broth was used. The NCCLS standardized method was published after much of the clinical work in this study had been performed using Mueller-Hinton broth, and it was decided to continue to use this diluent for the clinical tests and in the laboratory part of the study.

Inhibitory and bactericidal titres of the sera were performed as follows: $25 \mu \mathrm{L}$ volumes of serum were serially diluted twofold in MuellerHinton Broth (Oxoid Canada), and after dilution $25 \mu \mathrm{L}$ of inoculum was added to give a final inoculum density of $10^{5}$ to $10^{6} / \mathrm{mL}$. Oxacillin is usually preferred to cloxacillin for standardized in vitro testing because of its greater stability, but in the present study cloxacillin was used to preserve comparability between artificial and patient sera, most of whom were receiving cloxacillin. The inoculum was prepared by dilution of an overnight culture. The precise inoculum density was determined in each case by a colony count. The microtitre trays were incubated at $35^{\circ} \mathrm{C}$ for $20 \mathrm{~h}$, shaken, and reincubated for a further $4 \mathrm{~h}$ (6). Subcultures were then performed at $24 \mathrm{~h}$.

Subculture plates were inoculated with $10 \mu \mathrm{L}$ and incubated for $48 \mathrm{~h}$; the $99.9 \%$ endpoint was determined by the method of Pearson et al (7). Except where otherwise stated, subcultures were plated onto $5 \%$ sheep blood agar.

24 h kill measurements: These tests were all done in $1 \mathrm{~mL}$ volumes in $9 \mathrm{~mm}$ glass tubes, with starting inocula adjusted to $10^{6}$ colony forming units (cfu)/mL. For the 24 h kill measurements tubes were shaken at $20 \mathrm{~h}$ and subcultured at 24 h. Subculture plates were incubated for $48 \mathrm{~h}$. Endpoints were computed both by the method of Pearson et al (7), and by simple calculation.

Tests on patient sera: These were performed in the routine laboratory by the same technique as was used for the experimental sera.

Clinical study: There were 31 patients with Staph aureus infection covering a three year period, whose laboratory data met the criteria for inclusion. The clinical charts of the patients were reviewed by one of the authors (NEM) who was blinded to the chemotherapy and relevant laboratory results. Patient outcomes were assigned to one of three categories (better than expected, as expected or worse than expected), taking into account the site and nature of infection, presence or absence of bacteremia, age and immune status of the patient, presence or absence of serious underlying illness, and duration of illness at time of presentation. Diagnoses were as follows: osteomyelitis 22 patients, of whom eight had either bacteremia or evidence of infection elsewhere; three superficial or organ abscesses; three pyoarthritis; one intravenous line sepsis; one endocarditis; and one cellulitis. The charts were also reviewed independently by another investigator (AMRM) and the timing and magnitude of antibiotic doses determined from the nursing record. The requisition form for the serum inhibitory power/serum bactericidal titre (SIP/SBT) tests includes a box for time of sample. This timing was regarded as adequately established if it was specified on the requisition form or elsewhere in the chart. The routine laboratory worksheets for the patient SIP/SBT tests were examined. The SIP/SBT results recorded in the clinical part of the paper met the following criteria.

In patients on single antibiotic therapy the sample was taken within 90 mins of either an intravenous or oral dose of a betalactam antibiotic.

For patients on combination therapy the sample was taken within 90 mins of a betalactam dose and within $4 \mathrm{~h}$ of a rifampin dose.

Review of the laboratory worksheet records showed that the test was technically satisfactory.

\section{RESULTS}

Laboratory studies: It was observed early in this study that colonies derived from organisms which had been exposed to rifampin, with or without other antibiotics, grew more slowly than organisms exposed to vancomycin or cloxacillin alone. Frequently, colonies of organisms exposed to rifampin were invisible or too small to count after $24 \mathrm{~h}$ incubation, and $48 \mathrm{~h}$ incubation was required for full colony growth. This is illustrated in Figure 1 for a rifampin/vancomycin combination. In order to enhance the photographic image, this figure was prepared using trypticase soy agar, but the same effect was observed using blood agar. All of the strains in this study showed this effect, and as a result of this observation, subculture plates were incubated routinely for $48 \mathrm{~h}$.

Figure 2 shows the SIP/SBT values determined for 11 strains of Staph aureus against a single 
A

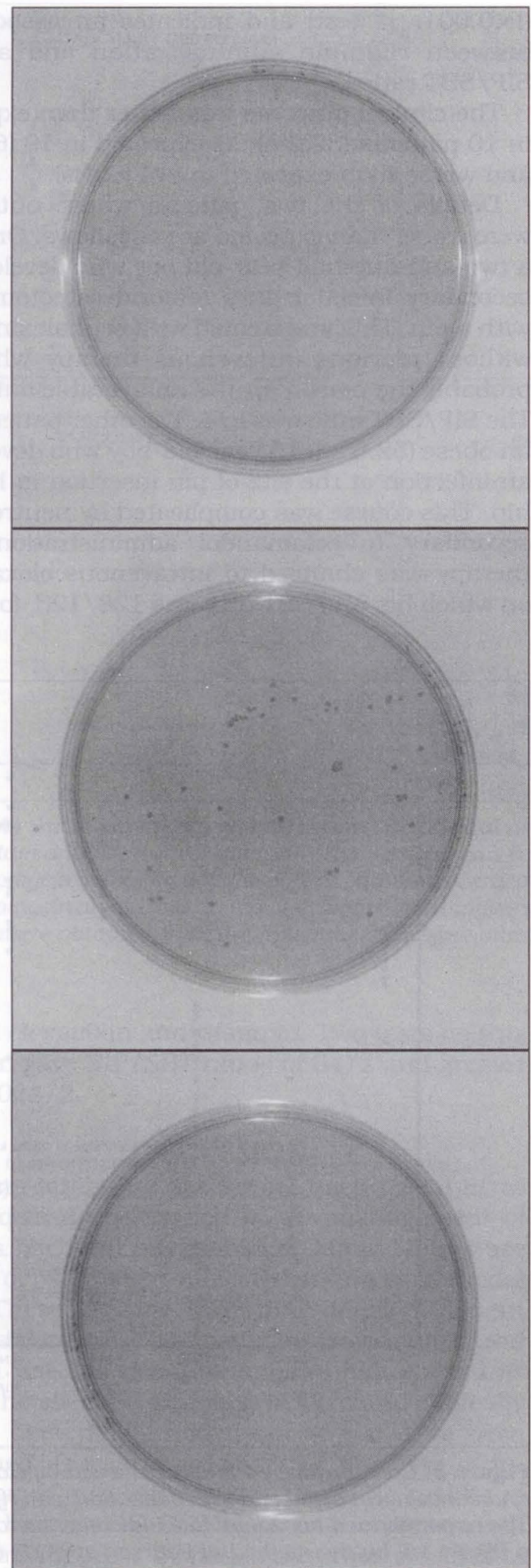

B

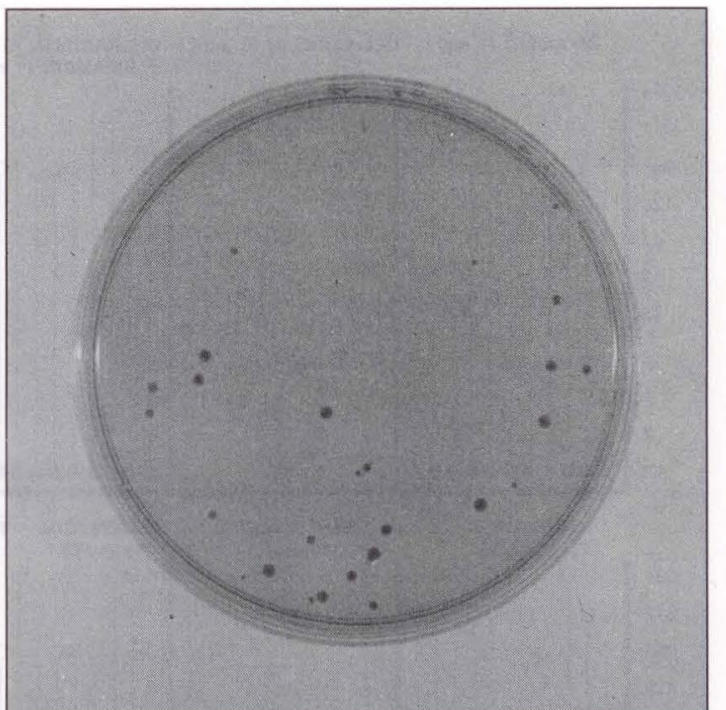

D

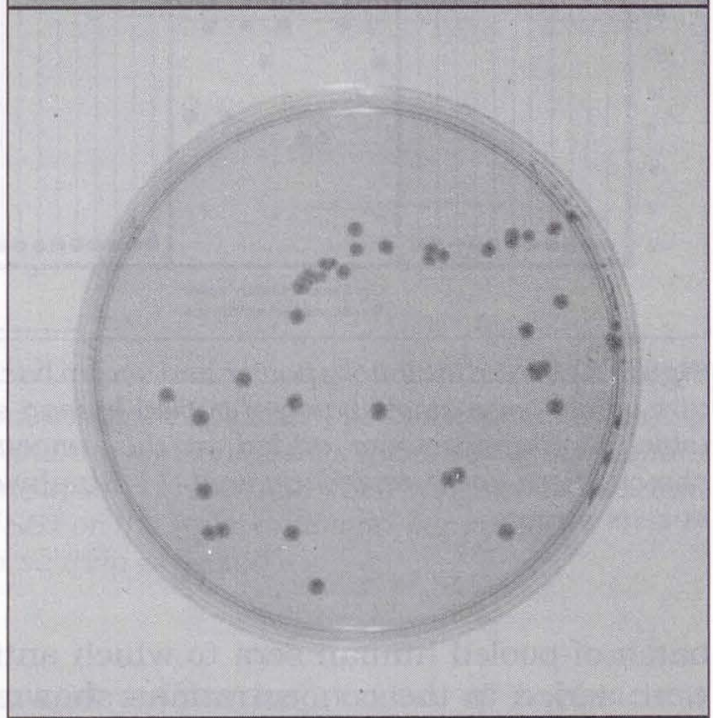

F

Figure 1) Surviving colonies on trypticase soy agar after $24 \mathrm{~h}$ exposure to vancomycin (10 mg/L) and/or rifampin 1 mg/L (strain ATCC 25923). A Rifampin subculture plate incubated $24 \mathrm{~h}$. B Rifampin subculture plate incubated $48 \mathrm{~h}$. C Vancomycin subculture plate incubated $24 \mathrm{~h}$. D Vancomycin subculture plate incubated $48 \mathrm{~h}$. E Vancomycin/rifampin subculture plate incubated $24 \mathrm{~h}$. F Vancomycin/rifampin subculture plate incubated $48 \mathrm{~h}$. Plate $\mathbf{C}$ shows colonies well formed at $24 \mathrm{~h}$; plates $\mathbf{A}$ and $\mathbf{E}$ show absence of visible growth at $24 \mathrm{~h}$. All plates show full colonial growth at $48 \mathrm{~h}$. Photographic conditions were constant 


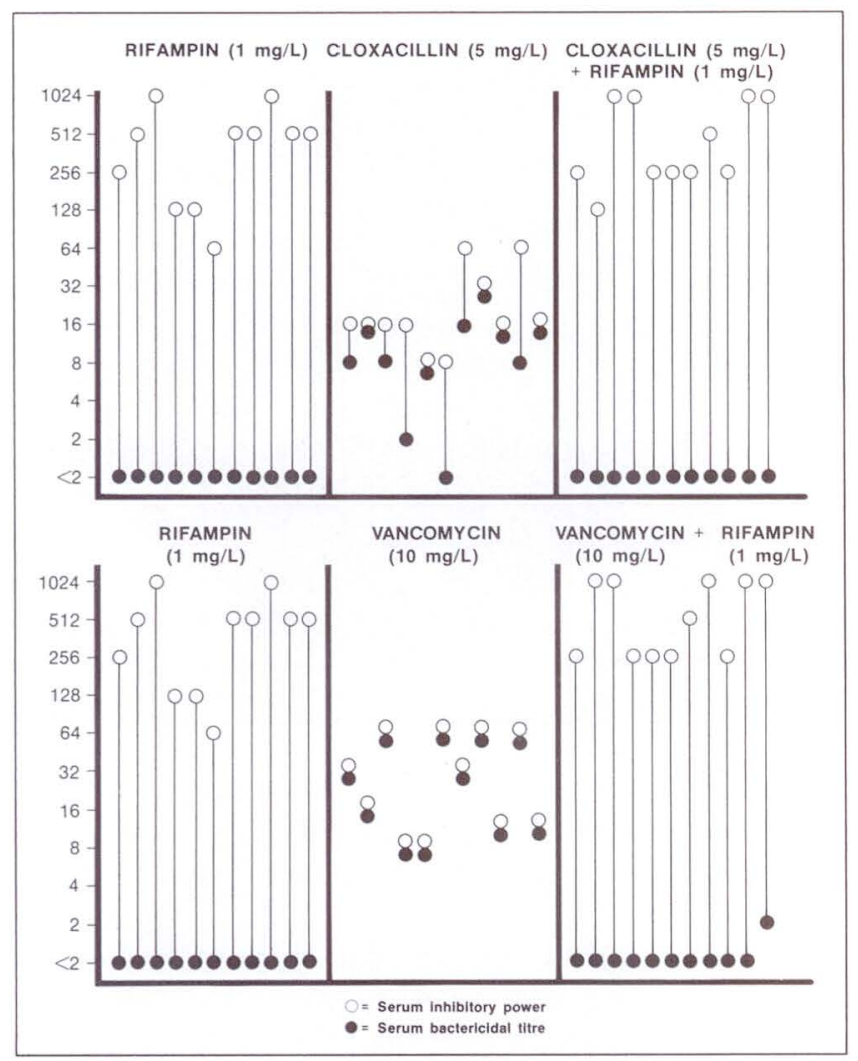

Figure 2) Serum inhibitory power and serum bactericidal titre values for a single batch of pooled human serum to which antibiotics were added at the concentrations shown. Sera were tested against 11 Staphylococcus aureus strains

batch of pooled human sera to which antibiotics were added to the concentrations shown in the figure (rifampin $1 \mathrm{mg} / \mathrm{L}$, cloxacillin $5 \mathrm{mg} / \mathrm{L}$ and vancomycin $10 \mathrm{mg} / \mathrm{L}$ ). With both cloxacillin alone and vancomycin alone, 10 of 11 strains had SIP/SBT ratios less than or equal to 8 . With all 11 strains the effect of the addition of rifampin to the serum was to increase the serum inhibitory power but reduce the serum bactericidal titre, thus increasing the SIP/SBT ratio.

The $24 \mathrm{~h}$ logarithmic kills achieved by each of the antibiotics alone and in combination are shown in Figure 3. These results are consistent with the results in Figure 2 and support the hypothesis that rifampin interferes with the bactericidal activity of cloxacillin and vancomycin.

Clinical study: In the clinical part of the study, 31 patients were reviewed. There were 48 sera studied from the 31 patients. Nine of 10 sera from patients receiving rifampin showed an SIP/SBT ratio greater than 8 (Figure 4 ). There were 38 sera taken from patients receiving either betalactam or vancomycin alone, of which only three gave an SIP/SBT ratio greater than 8 . The difference between these two groups was highly significant
$\left(\mathrm{P}<0.001, \chi^{2}\right.$ test $)$ and indicates an association between rifampin administration and a high SIP/SBT ratio.

The clinical outcome was better than expected in 10 patients (32.2\%), as expected in $19(61.2 \%)$ and worse than expected in two (6.4\%).

Details of the two patients whose outcomes were worse than expected are as follows: One was a two-and-one-half-year-old boy who developed a secondary infection in a femoral osteotomy site with a pin. This was treated with cephalexin alone without previous intravenous therapy which is probably the reason for the unfavorable outcome. The SIP/SBT ratio was $8 / 4$. The other patient was an obese $(52.5 \mathrm{~kg}) 15$ year-old-boy who developed an infection at the site of pin insertion in his left hip. This course was complicated by neutropenia secondary to cefamandol administration. The therapy was changed to intravenous cloxacillin, on which his SIP/SBT titre was 128/128, followed

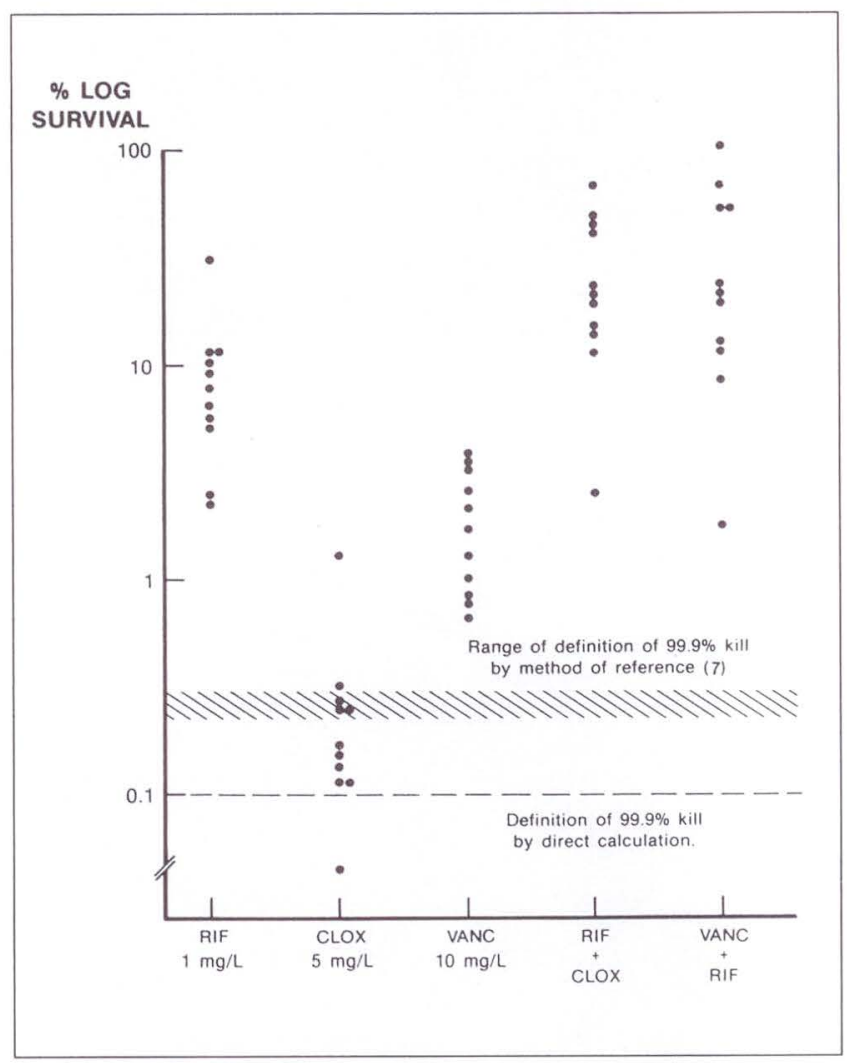

Figure 3) Comparative $24 \mathrm{~h}$ kills achieved by cloxacillin and vancomycin alone and in combination with rifampin. The upper shaded horizontal line indicates the range for a $99.9 \%$ kill by the method of Pearson et al (7) and the lower line is derived from direct calculation of the expected number of colonies. Eleven strains of Staphylococcus aureus were exposed for $24 \mathrm{~h}$ to cloxacillin $(C L O X)(5 \mathrm{mg} / \mathrm{L})$, vancomycin (VANC) $(10 \mathrm{mg} / \mathrm{L})$, and rifampin (RIF) (1 $\mathrm{mg} / \mathrm{L})$ alone and in combination as shown. Starting inoculum was adjusted to approximately $10^{6} / \mathrm{mL}$ and counted 


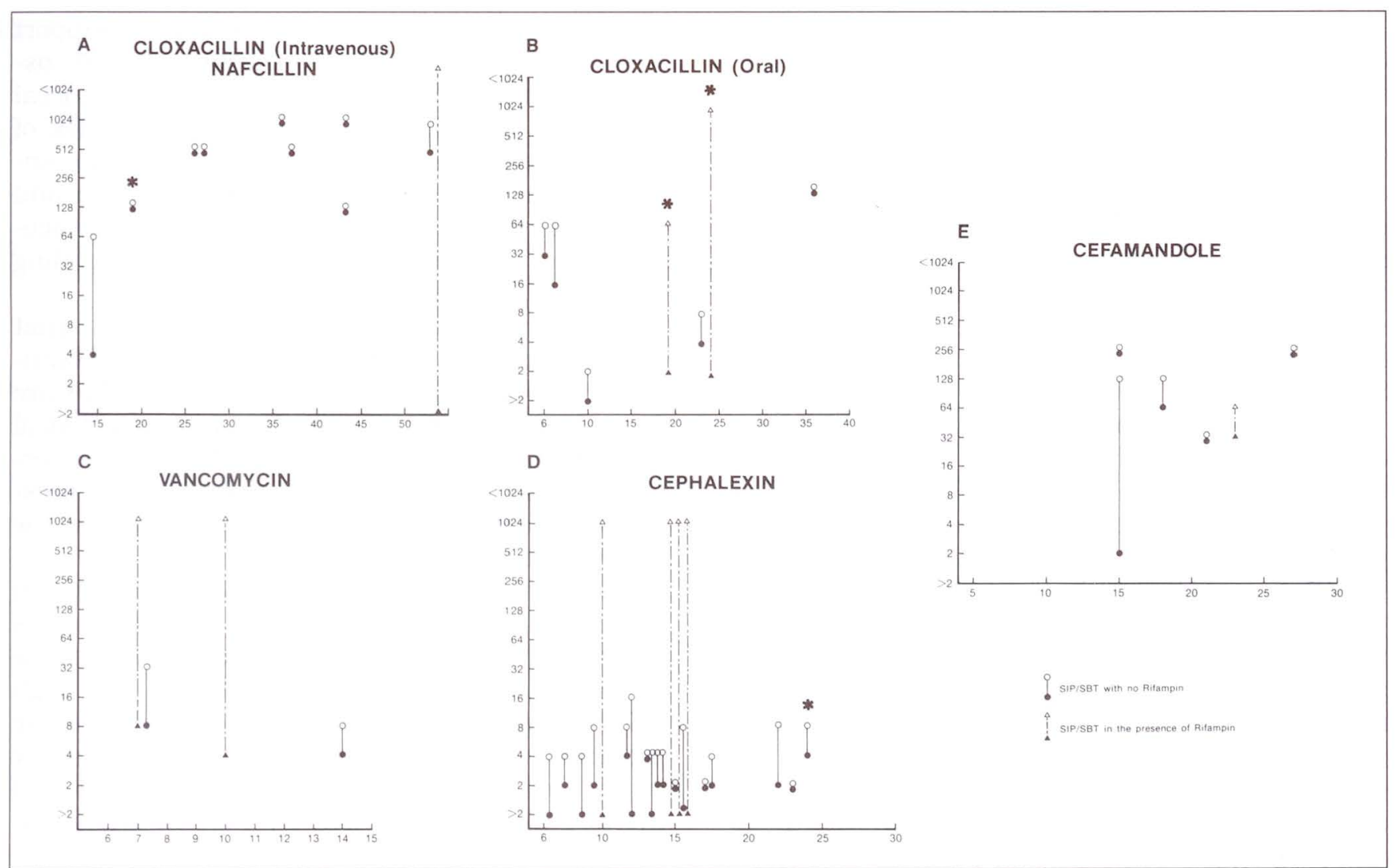

Figure 4) Serum inhibitory power/serum bactericidal titre (SIP/SBT) values given by patient sera. Patients received a betalactam antibiotic or vancomycin. The vertical axes represent titres and the horizontal axes the doses of betalactam or vancomycin in $\mathrm{mg} / \mathrm{kg}$ body weight. Continuous vertical lines between circles represent SIP/SBT ratios on betalactam or vancomycin alone, and dotted lines between triangles represent SIP/SBT on the same antibiotic plus rifampin. *These results were obtained from the two patients whose outcomes were worse than expected

by oral cloxacillin and rifampin. Two tests on this regimen gave SIP/SBT ratios of $64 / 2$ and greater than $1024 / 2$.

\section{DISCUSSION}

Serum inhibitory and serum bactericidal titres are frequently performed in the management of serious bacterial infections (1). Many factors are known or assumed to affect the serum bactericidal titre. These include inoculum density, diluent composition, growth phase of initial inoculum and criteria used to define endpoints $(6,8,9)$. In this study the effects of rifampin in vitro and clinically on the bactericidal activity of serum have been examined. It was found that the duration of incubation of subcultures can affect the results of serum bactericidal titre tests in the presence of rifampin. Figure 1 demonstrates that colonies of surviving organisms exposed to rifampin are much smaller than controls at $24 \mathrm{~h}$ and may be invisible or too small to count. This phenomenon was seen in tests where organisms were exposed to rifampin either alone or in combination with other antibiotics, and could result in missed small colonies and a false impression of bactericidal activity. For this reason, subculture plates should be incubated for $48 \mathrm{~h}$ as in this study.

The present laboratory results using a $48 \mathrm{~h}$ incubation period for subcultures indicate that the administration of rifampin with vancomycin or with an oxazolyl penicillin (cloxacillin) increases serum inhibitory activity but reduces bactericidal activity. The laboratory results obtained in the SIP/SBT tests and in the $24 \mathrm{~h}$ killing experiments showed that rifampin exerts an inhibitory effect on the bactericidal activity of both cloxacillin and vancomycin (Figures 2,3).

Antagonism in vitro between rifampin and oxazolyl penicillins (2-4) and between rifampin and vancomycin $(4,10)$ has been a common but not universal finding (11-14). Some of the reports investigating these interactions do not specify the duration of incubation of subculture plates and, as demonstrated, incomplete incubation of subculture plates may sometimes give rise to inconsistent results when rifampin is present.

The clinical study results show that serum bactericidal titre values observed with single betalac- 
tam or vancomycin regimens are within three dilutions of the serum inhibitory power values in the majority of tests. Patients receiving rifampin, however, demonstrate a raised serum inhibitory power, an increased SIP/SBT ratio, and a decreased serum bactericidal titre (Figure 4), reproducing the results of the in vitro part of the study shown in Figures 2 and 3. Although the total number of patients reviewed was not large, the low serum bactericidal titre and high SIP/SBT ratio seen with rifampin combination therapy was not associated with a poor outcome.

In the present experiments and in the observations from clinical specimens it has been shown that the killing of Staph aureus by an oxazolyl penicillin and by vancomycin is retarded by the presence of rifampin. Bacterial death still occurs with the combination, but at a reduced rate, and the endpoint chosen for the definition of bactericidal activity, $99.9 \%$ in $24 \mathrm{~h}$, is arbitrary. It is possible that an antibiotic or a combination which is not bactericidal according to this definition is still sufficiently lethal to the organism to be clinically effective. The present results do not necessarily indicate, therefore, that rifampin therapy is inappropriate for conditions requiring bactericidal

ACKNOWLEDGEMENTS: The authors acknowledge the excellent technical support of Evelyne Kokoskin-Nelson, and thank Jean Morocz for the preparation of this manuscript.

\section{REFERENCES}

1. Wolfson JS, Swartz MN. Drug therapy. Serum bactericidal activity as a monitor of antibiotic therapy. N Engl J Med 1985;312:968-75.

2. Zinner SH, Lagast H, Klastersky J. Antistaphylococcal activity of rifampin with other antibiotics. J Infect Dis 1981;144:365-71.

3. Van der Auwera P, Klastersky J. In vitro study of the combination of rifampin with oxacillin against Staphylococcus aureus. Rev Infect Dis 1983;5(Suppl 3):S509-14.

4. Hackbarth CJ, Chambers HF, Sande MA. Serum bactericidal activity of rifampin in combination with other antimicrobial agents against Staphylococcus aureus. Antimicrob Agents Chemother 1986;29:611-3.

5. National Committee for Clinical Laboratory Standards. Methodology for the serum bactericidal test: Proposed guideline. NCCLS document M21-P. Villanova, Pennsylvania: National Committee for Clinical Laboratory Standards, 1987.

6. Taylor PC, Schoenknecht FD, Sherris JC, Linner EC. Determination of minimal bactericidal concentrations of oxacillin for Staphylococcus aureus: Influence and significance of technical factors. Antimicrob Agents Chemother 1983;23:142-50. activity, and there is clinical evidence to support the use of this drug in endocarditis (15-17), osteomyelitis (18), and experimental staphylococcal infections (19). In two animal model studies of chronic Staph aureus osteomyelitis, rifampin enhanced the clinical efficacy of vancomycin and betalactams, although in both studies antagonism was shown in vitro in the corresponding strains of Staph aureus $(20,21)$.

In summary the present results indicate that combinations of rifampin and betalactam antibiotics or vancomycin yield test results that are difficult to interpret and may not relate to clinical efficacy. The authors also suggest that the determination of serum bactericidal titre in the presence of rifampin requires $48 \mathrm{~h}$ incubation of the subculture plates.

The clinical significance of the reduction in bactericidal activity induced by rifampin in this study is not known, but did not appear to be adverse. Low serum bactericidal titre and high SIP/SBT ratios should probably be expected in the presence of rifampin and should not necessarily be regarded as an indication for modification of therapy unless warranted by the clinical situation.

7. Pearson RD, Steigbigel RT, Davis HT, Chapman SW. Method for reliable determination of minimal lethal antibiotic concentrations. Antimicrob Agents Chemother 1980;18:699-708.

8. Reller LB. The serum bactericidal test. Rev Infect Dis 1986;8:803-8.

9. Stratton CW. Serum bactericidal test. Clin Microbiol Rev 1988;1:119-26.

10. Watanakunakorn C, Guerriero JC. Interaction between vancomycin and rifampin against Staphylococcus aureus. Antimicrob Agents Chemother 1981;19:1089-91.

11. Bayer AS, Morrison JO. Disparity between timedkill and checkerboard methods for determination of in vitro bactericidal interactions of vancomycin plus rifampin versus methicillin-susceptible and resistant Staphylococcus aureus. Antimicrob Agents Chemother 1984;26:220-3.

12. Tuazon CU, Miller $\mathrm{H}$. Comparative in vitro activities of teichomycin and vancomycin alone and in combination with rifampin and aminoglycosides against staphylococci and enterococci. Antimicrob Agents Chemother 1984;25:411-2.

13. Tuazon CU, Lin MYC, Sheagren JN. In vitro activity of rifampin alone and in combination with nafcillin and vancomycin against pathogenic strains of Staphylococcus aureus. Antimicrob Agents Chemother 1978;13:759-61.

14. Varaldo PE, Debbia E, Schito GC. In vitro activity of teichomycin and vancomycin alone and in combination with rifampin. Antimicrob Agents Chemother 1983;23:402-6. 
15. Faville RJ Jr, Zaske DE, Kaplan EL, Crossley K, Sabath LD, Quie PG. Staphylococcus aureus endocarditis. Combined therapy with vancomycin and rifampin. JAMA 1978;240:1963-5.

16. Massanari RM, Donta ST. The efficacy of rifampin as adjunctive therapy in selected cases of staphylococcal endocarditis. Chest 1978;73:371-5.

17. Van der Auwera P, Meunier-Carpentier F, Klastersky J. Clinical study of combination therapy with oxacillin and rifampin for staphylococcal infections. Rev Infect Dis 1983;5(Suppl 3):515-22.

18. Norden CW, Bryant R, Palmer D, Montgomerie JZ, Wheat J. Chronic osteomyelitis caused by Staphylococcus aureus: Controlled clinical trial of nafcillin therapy and nafcillin-rifampin therapy. South Med J 1980;79:947-51

19. Mandell GL, Moorman DR. Treatment of experimental staphylococcal infections: Effect of rifampin alone and in combination on development of rifampin resistance. Antimicrob Agents Chemother 1980; 17:658-62.

20. Norden CW, Shaffer M. Treatment of experimental chronic osteomyelitis due to Staphylococcus aureus with vancomycin and rifampin. $\mathrm{J}$ Infect Dis 1983;147:352-7.

21. Bayer AS, Lam K. Efficacy of vancomycin and rifampin in experimental aortic valve endocarditis due to methicillin resistant Staphylococcus aureus: In vitro-in vivo correlations.

J Infect Dis 1985;151:157-65. 


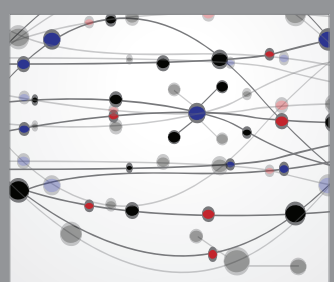

The Scientific World Journal
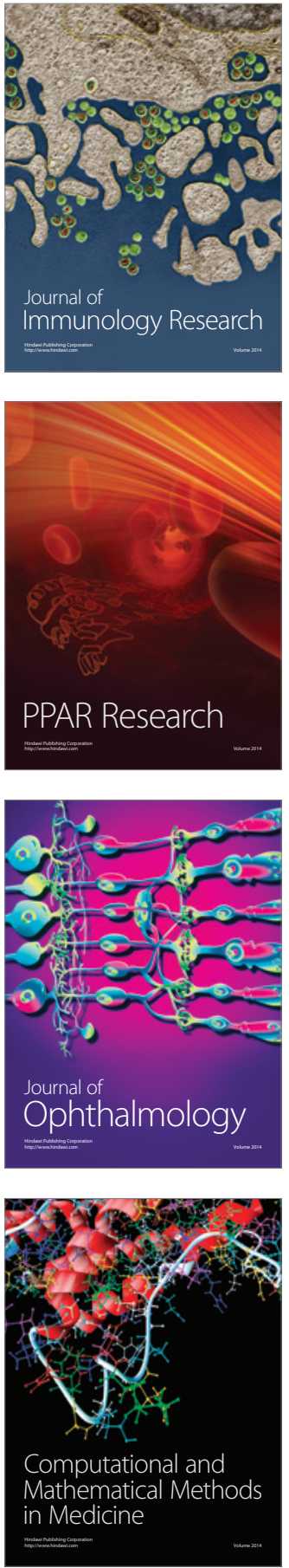

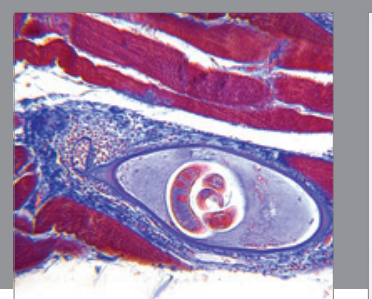

Gastroenterology Research and Practice

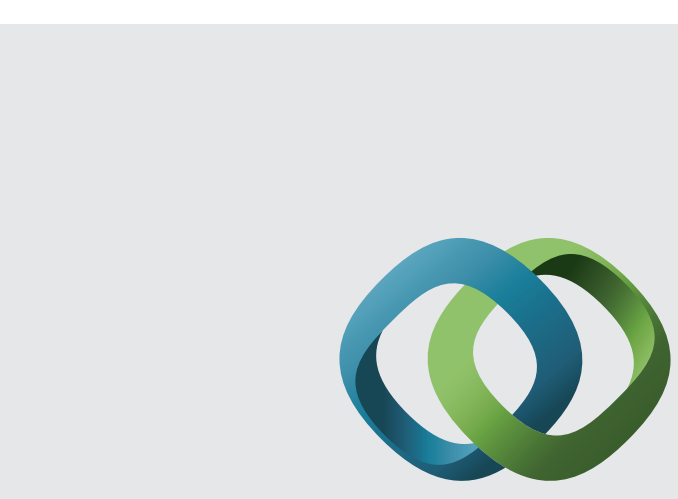

\section{Hindawi}

Submit your manuscripts at

http://www.hindawi.com
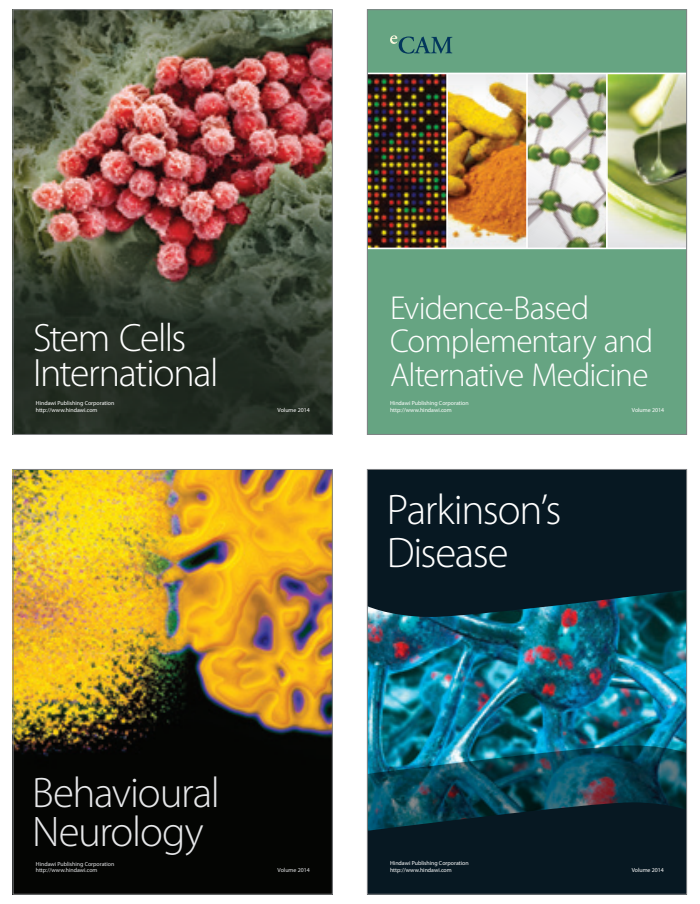
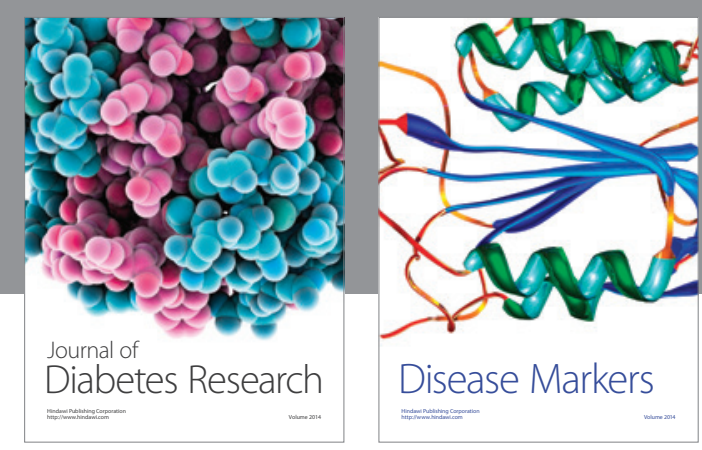

Disease Markers
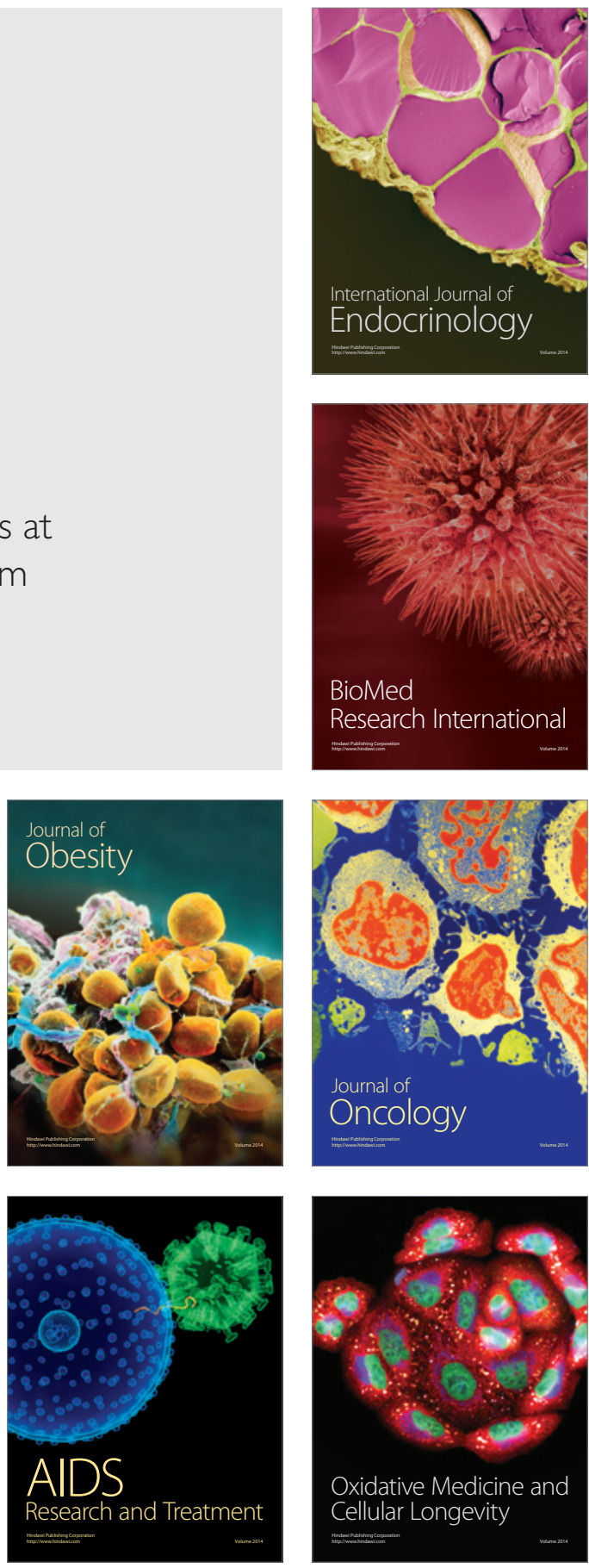